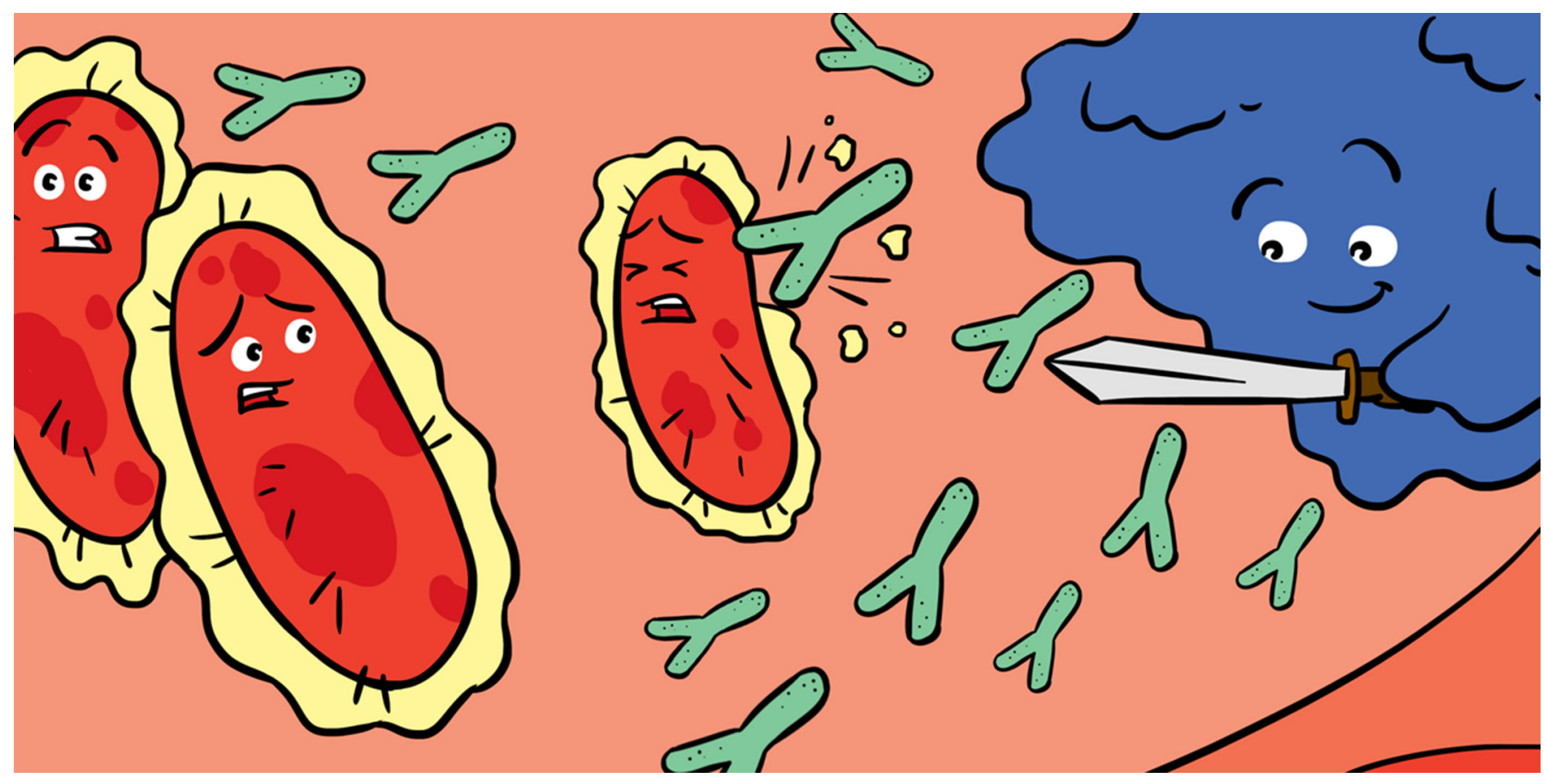

\title{
TREATING BACTERIAL INFECTIONS WITH A PROTEIN FROM A VIRUS
}

\section{Hugo Oliveira * and Joana Azeredo *}

CEB-Centre of Biological Engineering, University of Minho, Braga, Portugal

YOUNG REVIEWER:

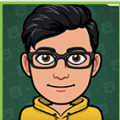

NEEL

AGE: 15
Harmful bacteria are microscopic organisms that can sometimes make you very sick. Usually, when harmful bacteria enter our bodies, they are rapidly detected by the immune system, which kills these invaders. However, some bacteria can trick the immune system by coating themselves with substances that make them invisible to the immune system. These disguises are called capsules. However, there are some proteins called capsular depolymerases that can remove the capsules from these harmful bacteria, exposing the bacteria to the immune system, which can then kill them. Therefore, capsular depolymerases can help the immune system to kill harmful bacteria. In this article, we explain where capsular depolymerases are found in nature, how they are different from antibiotics, and how they could be used to treat bacterial diseases.

\section{GOOD BACTERIA VS. BAD BACTERIA}

Have you seen one bacterium? Not with your naked eye! Bacteria are microorganisms that can only be seen using a microscope. These tiny living organisms are everywhere on earth, even in the most extreme 
PATHOGENIC

BACTERIA

Organisms that cause disease in living beings

IMMUNE SYSTEM

Complex defense mechanisms made of cells and proteins that protect organisms against infections.

\section{ANTIGEN}

Molecule located at the surface of the bacterial cell that can bind to antibodies.

\section{ANTIBODY}

Protein of the immune system that circulate in the blood, identifies and neutralize foreign threats such as pathogenic bacteria.

\section{CAPSULE}

The outermost layer of most bacterial cells. environments, like volcanoes and deep oceans. Bacteria also live in our bodies, mostly in the intestines, in the mouth, and on the skin. Many bacteria help us to stay healthy, by digesting the foods we eat and helping us to absorb the nutrients, or by protecting our skin from other, dangerous microorganisms. Some dangerous microorganisms, called pathogenic bacteria, can cause diseases. Pathogenic bacteria can be transmitted through contaminated food or water, or through the air when an infected person coughs, sneezes, or talks. That is why it is recommended to cover your mouth with your forearm when you cough or sneeze. Pathogenic bacteria can also be transmitted by objects, and that is why it is important to have good high hygiene habits, like washing your hands and brushing your teeth properly. Harmful bacteria can make us sick by infecting the stomach, ears, lungs, teeth, or other organs.

\section{WHAT IS THE IMMUNE SYSTEM AND WHAT DOES IT DO?}

Every day, we are under attack by billions of bacteria that are trying to make our bodies their home. Therefore, the human body has developed an immune system to protect us from harmful organisms, like the pathogenic bacteria that make us ill. The immune system is super complex and is made of an army of little guards, soldiers, and snipers that team up to protect us from getting sick. So, what happens in the case of an infection? Initially, the bacteria that enter the body fly under the radar-they may not be immediately detected by the immune system. However, as the bacteria multiply, they start damaging the bodily environment around them and the immune system is activated. The immune system detects specific molecules called antigens, which are located on the surfaces of the bacteria, and tries to eliminate the threat as quickly as possible. There are two different strategies the immune system uses to control pathogenic bacteria. The quickest, called the innate immune system, is the first line of defense, composed of cells that "eat" the invaders, to try to immediately prevent their spread throughout the body. The adaptive immune system, which becomes activated a little later, enhances the response against the invaders by producing antibody molecules that target the pathogenic bacteria, among other specialized strategies. Because antibodies stay in our bodies for a long time, the immune system can react more quickly if the same pathogen infects us again. Vaccines take advantage of this strategy.

\section{HOW BACTERIAL PATHOGENS AVOID THE IMMUNE SYSTEM}

Pathogenic bacteria are smart and can use various strategies to escape the immune system. Both helpful and pathogenic bacterial are surrounded by a coating of sugars called the capsule. The capsule can 
help the bacteria to colonize different environments or cells, to hide from natural predators such as viruses, or to avoid the immune system. Using the capsule as a protective cover is a common tactic for evading the immune system.

Bacteria can produce capsules from molecules that are naturally present in the human body. Because they are made from human molecules, capsules are not detected by the immune system, so they conceal the bacterial antigens that the immune system would usually recognize and attack. Therefore, capsules make pathogenic bacteria invisible to the immune system. For example, Acinetobacter baumannii is a deadly bacterium that produces a capsule that prevents it from being eaten by cells of the innate immune system [1, 2]. These bacteria produce their capsule using a number of different materials, which further confuses the immune system and makes the bacterial antigens even harder to recognize [3]. Capsules are a successful mechanism that has evolved in bacteria to help them enter into and survive within the human body.

CAPSULAR

DEPOLYMERASE

Proteins located at the bacteriophage's tails that bind and degrade bacterial capsules.

\section{BACTERIOPHAGE}

Viruses and natural predators of bacterial. They are the most abundant biological entities of Earth.

\section{CAPSULAR DEPOLYMERASE-A PROTEIN THAT UNMASKS PATHOGENIC BACTERIA}

What if there was a magical protein that could break down bacterial capsules? These proteins could be used to remove the capsules of pathogenic bacteria and expose the pathogens to the immune system. These proteins actually exist in nature! They are called capsular depolymerases and, curiously, they can be found in the tails of viruses that attack bacteria, which are called bacteriophages. The lifecycle of a bacteriophage has four main stages. First, the bacteriophage must locate and recognize a suitable bacteria by binding to specific antigens on the bacterial surface. The bacteriophage then infects its DNA into the bacterial cell. The DNA reproduces inside the bacterial cell and produces more bacteriophages. Finally, the bacterial cell wall bursts and the newly formed bacteriophages are released (Figure 1A).

Capsular depolymerase is one of the most important proteins that bacteriophages use to complete their lifecycle, because this protein helps the bacteriophage to break down the bacterial capsule enough to expose the antigens it must bind to. It is possible to isolate capsular depolymerases from bacteriophages and use them as medicines to strip the capsules off of pathogenic bacteria, thereby weakening the bacteria so that they can easily be controlled by the immune system (Figure 1B).

\section{ARE CAPSULAR DEPOLYEMRASES BETTER THAN ANTIBIOTICS?}

But could not we just use antibiotics to control the pathogenic bacteria that make us sick? For the most part yes, we can! Antibiotics are 
Figure 1

(A) Bacteriophages, viruses that infect bacteria, must first recognize and bind to antigens on the bacterial cell. They use capsular depolymerase proteins to break down the bacterial capsule to expose those binding sites, then they inject their DNA into the bacterial cell. More bacteriophages are produced within the bacteria cell, until the cell bursts and releases them. (B) Capsular depolymerases can be isolated from bacteriophages and used to break down bacterial capsules and expose pathogenic bacteria to the immune system, so that they can be destroyed.

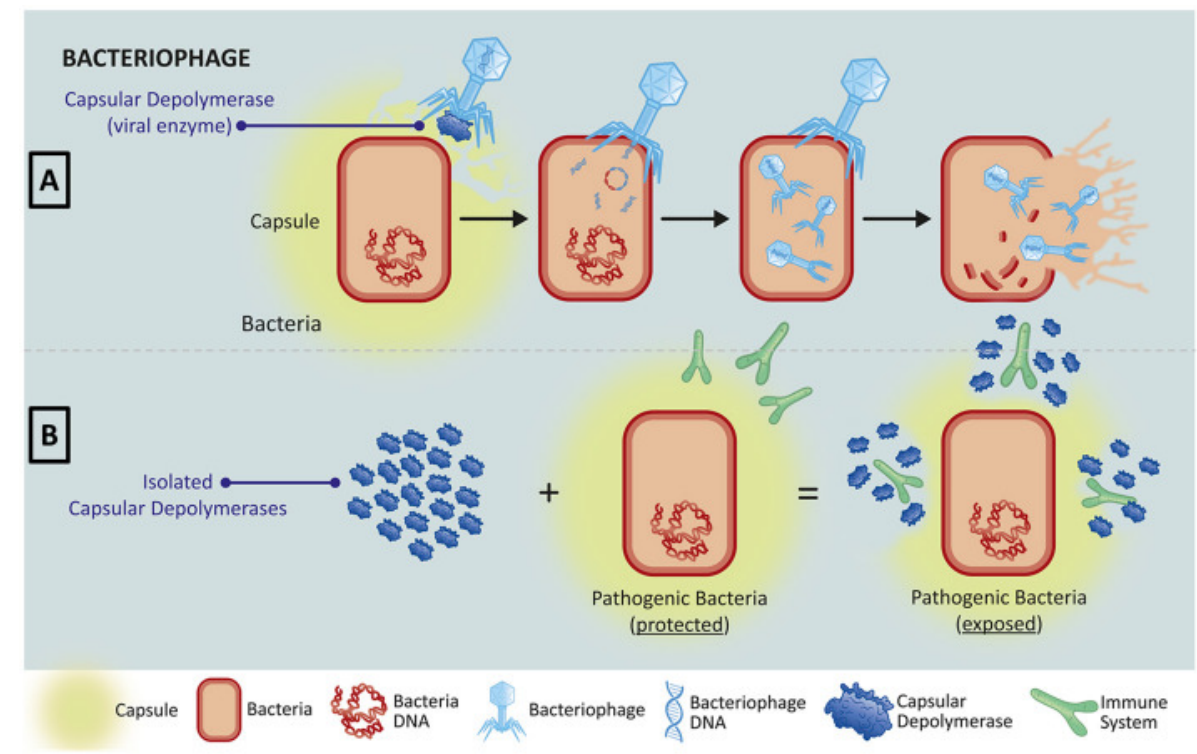

Figure 1

wonderful weapons to control bacterial diseases. If you get a bacterial infection, it is likely that your doctor will give you an antibiotic to treat it. But antibiotics are not perfect medicines. They kill bacteria by entering them and inhibiting their growth, but they do not distinguish good from bad bacteria and they often kill both. Killing the good bacteria can interfere with our health, too. Also, antibiotics have been overused for many years, which has made many bacteria resistant to several types of antibiotics. That is why some antibiotic treatments no longer work to kill certain bacteria.

Capsular depolymerases, on the other hand, are highly specific, which means they only target the pathogen that is causing the disease. Therefore, they do not interfere with the helpful bacteria in the body. Also, since capsular depolymerases do not directly kill the bacteria like some antibiotics do, it is more difficult for the bacteria to evolve to become resistant to these proteins. Capsular depolymerases act by removing the capsules from bacteria and exposing their antigens, and then the immune system does the job of killing the bacteria and controlling the infection.

Unfortunately, treatment of bacterial infections with capsular depolymerases is not yet available. It is still at the development stage and more tests need to be done to make sure that this new treatment works in humans and that it is safe. We believe that capsular depolymerases will be a useful technology to combat bacterial infections in the future. We are sharing this exciting medical development with you, with the hope that it will soon save the lives of many people who are infected with pathogenic bacteria! 


\section{REFERENCES}

1. Oliveira, H., Costa, A. R., Ferreira, A., Konstantinides, N., Santos, S. B., Boon, M., et al. 2019. Functional analysis and antivirulence properties of a new depolymerase from a myovirus that infects acinetobacter baumannii capsule K45. J Virol. 93:e01163-18. doi: 10.1128/JVI.01163-18

2. Oliveira, H., Mendes, A., Fraga, A. G., Ferreira, A., Pimenta, A. I., Mil-Homens, D., et al. 2019. K2 capsule depolymerase is highly stable, is refractory to resistance, and protects larvae and mice from acinetobacter baumannii sepsis. Appl Environ Microbiol. 85:e00934-19. doi: 10.1128/AEM.00934-19

3. Oliveira, H., Costa, A. R., Konstantinides, N., Ferreira, A., Akturk, E., Sillankorva, S., et al. 2017. Ability of phages to infect acinetobacter calcoaceticus-acinetobacter baumannii complex species through acquisition of different pectate lyase depolymerase domains. Environ Microbiol.

19:5060-77. doi: 10.1111/1462-2920.13970

SUBMITTED: 12 January 2021; ACCEPTED: 09 December 2021;

PUBLISHED ONLINE: 24 December 2021.

EDITED BY: Valeria Costantino, University of Naples Federico II, Italy

CITATION: Oliveira H and Azeredo J (2021) Treating Bacterial Infections With a Protein From a Virus. Front. Young Minds 9:648764. doi: 10.3389/frym.2021.648764

CONFLICT OF INTEREST: The authors declare that the research was conducted in the absence of any commercial or financial relationships that could be construed as a potential conflict of interest.

COPYRIGHT @ 2021 Oliveira and Azeredo. This is an open-access article distributed under the terms of the Creative Commons Attribution License (CC BY). The use, distribution or reproduction in other forums is permitted, provided the original author(s) and the copyright owner(s) are credited and that the original publication in this journal is cited, in accordance with accepted academic practice. No use, distribution or reproduction is permitted which does not comply with these terms.

\section{YOUNG REVIEWER}

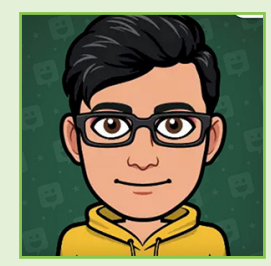

\section{NEEL, AGE: 15}

Neel loves golf, playing the guitar, and gaming on his X-box. He is excited about marine biology and engineering.

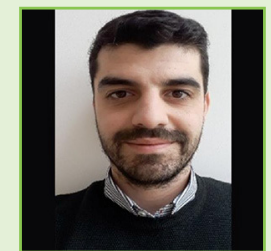

\section{AUTHORS}

\section{HUGO OLIVEIRA}

I am a assistant researcher in microbiology working in Portugal. Ever since I became a scientist, I have been interested in exploiting nature's best resources to kill pathogenic bacteria. I am therefore using bacteriophages, which are natural bacterial predators that evolved over millions of years of evolution, to develop weapons to fight antibiotic-resistant bacteria. *hugooliveira@ceb.uminho.pt 


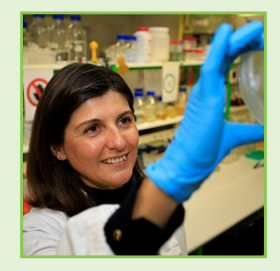

\section{JOANA AZEREDO}

I am a professor and a scientist at the University of Minho in Portugal. My research group and I have been studying bacteriophages for many years. We are interested in understanding how bacteriophages, the viruses of bacteria, kill bacterial cells. This knowledge is helping us to develop new biotechnological approaches to combat diseases caused by pathogenic bacteria, inspired by the secret weapons of bacteriophages. *jazeredo@deb.uminho.pt 